\title{
Metformin synergizes with rapamycin to inhibit the growth of pancreatic cancer in vitro and in vivo
}

\author{
JIA-WEI ZHANG, FAN ZHAO and QING SUN \\ Department of Oncology, Wuxi No. 2 People's Hospital, Affiliated to Nanjing Medical University, \\ Wuxi, Jiangsu 214000, P.R. China
}

Received February 28, 2017; Accepted October 13, 2017

DOI: $10.3892 / 01.2017 .7444$

\begin{abstract}
Previous studies have suggested that metformin may improve the survival rate of patients with pancreatic cancer (PC) by regulating the adenosine monophosphate-activated protein kinase/mammalian target of rapamycin (mTOR) signaling pathway. Rapamycin specifically targets mTOR. In the present study, the efficacy of metformin and rapamycin in isolation and combination were investigated for the treatment of PC. The efficacy of metformin and rapamycin in reducing the proliferation of PC cell line SW1990 in vitro and in vivo was evaluated. It was revealed that metformin $(10 \mathrm{mmol} / \mathrm{l})+$ rapamycin $(2 \mathrm{ng} / \mathrm{ml})$, metformin $(15 \mathrm{mmol} / \mathrm{l})+\operatorname{rapamycin}(20 \mathrm{ng} / \mathrm{ml})$ and metformin $(20 \mathrm{mmol} / \mathrm{l})+$ rapamycin $(200 \mathrm{ng} / \mathrm{ml})$ significantly inhibited the viability of PC cells compared with untreated cells. Additionally, metformin $(20 \mathrm{mmol} / \mathrm{l})+$ rapamycin (200 ng/ml) significantly suppressed the expression of phosphorylated mTOR compared with metformin or rapamycin alone. Using a xenograft tumor model, it was revealed that combination treatment significantly inhibited the growth of PC cells compared with monotherapy. The present study revealed that a combination of metformin and rapamycin synergistically inhibited the growth of $\mathrm{PC}$ in vitro and in vivo and may be a potential treatment option for patients with PC.
\end{abstract}

\section{Introduction}

Pancreatic cancer (PC) has a high mortality rate; its 5-year survival rate is between 7 and $8 \%$ (1). The estimated number of new cases of PC in China in 2015 was 90,100 and the estimated number of reported mortalities from the disease was 79,400 (2). The incidence and mortality rates of male patients with PC has demonstrated an upward trend from 2010 to 2011 (2). PC is primarily treated with chemotherapeutic drugs, which may result in side effects and potential drug resistance that can

Correspondence to: Dr Fan Zhao, Department of Oncology, Wuxi No. 2 People's Hospital, Affiliated to Nanjing Medical University, 68 Zhongshan Road, Wuxi, Jiangsu 214000, P.R. China

E-mail: zhaofan1958@yeah.net

Key words: metformin, rapamycin, pancreatic cancer further lead to patient mortality (3). The current standard drug for chemotherapy to treat pancreatic cancer is gemcitabine; however, its efficacy is far from satisfactory (3). To date, there is no other agent that has promoted a clinically meaningful prolongation of overall survival (3). The identification of a novel therapy for this highly aggressive disease is required.

Retrospective studies have suggested that metformin may reduce the risk and improve the prognosis of patients with PC (4-7). It has been demonstrated that metformin activates adenosine monophosphate (AMP)-activated protein kinase (AMPK), which then inhibits the mammalian target of rapamycin (mTOR) signaling pathway (8-11). The mTOR and AMPK signaling pathways control the mammalian cells' energy status [adenosine triphosphate (ATP)/AMP ratio] and regulate cell growth (12). Inhibition of mTOR has been demonstrated to reduce the growth of PC cells (12). Rapamycin specifically inhibits mTOR and thus inhibits the proliferation and survival of PC cells (12).

The present study aimed to explore the efficacy of combined metformin and rapamycin therapy for the treatment of PC.

\section{Materials and methods}

Reagents. L-15 medium and fetal bovine serum (FBS) were obtained from Gibco (Thermo Fisher Scientific, Inc., Waltham, MA, USA). Antibodies directed against vascular endothelial growth factor (VEGF; sc-7269) were obtained from Santa Cruz Biotechnology, Inc. (Dallas, TX, USA). Antibodies directed against AMPK (\#5832), phosphorylated (p)-AMPK ${ }^{\text {Thr172 }}$

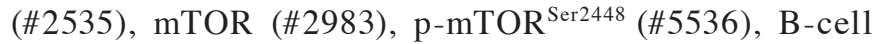
lymphoma-2 (Bcl-2; \#15071), epidermal growth factor receptor (EGFR) (\#4267), $\beta$-actin (\#4970), anti-rabbit immunoglobulin (Ig)G, HRP (horseradish peroxidase-conjugated)-linked antibody (\#7074), and anti-mouse IgG, HRP-linked antibody (\#7076) were obtained from Cell Signaling Technology, Inc. (Danvers, MA, USA). All other reagents, unless stated otherwise, were obtained from Sigma-Aldrich (Merck KGaA, Darmstadt, Germany).

Cell culture. The PC cell line SW1990 was acquired from the Type Culture Collection of the Chinese Academy of Sciences (Shanghai, China). It was maintained in L-15 medium with $10 \%$ heat-inactivated FBS and $1 \%$ penicillin/streptomycin at $37^{\circ} \mathrm{C}$ in a $95 \%$ humidified atmosphere. 
MTT assay. PC cell viability was measured using a MTT assay. SW1990 cells were seeded in 96-well plates at a density of $10^{5} / \mathrm{ml}$ and allowed to adhere overnight at $37^{\circ} \mathrm{C}$ and treated with PBS, metformin $(5,10,15$, and $20 \mathrm{mmol} / \mathrm{l})$, rapamycin $(0.2,2,20$, and $200 \mathrm{ng} / \mathrm{ml})$ and their combinations: A, metformin $(5 \mathrm{mmol} / \mathrm{l})+\operatorname{rapamycin}(0.2 \mathrm{ng} / \mathrm{ml})$; $\mathrm{B}$, metformin $(10 \mathrm{mmol} / \mathrm{l})+$ rapamycin $(2 \mathrm{ng} / \mathrm{ml}) ; \mathrm{C}$, metformin $(15 \mathrm{mmol} / \mathrm{l})+\operatorname{rapamycin}(20 \mathrm{ng} / \mathrm{ml})$; and $\mathrm{D}$, metformin $(20 \mathrm{mmol} / \mathrm{l})+$ rapamycin $(200 \mathrm{ng} / \mathrm{ml}))$ respectively. A total of $5 \mathrm{mg} / \mathrm{ml}$ MTT solution was added to each well. The cell viability was determined by measuring the absorbance of formazan which was dissolved in dimethyl sulfoxide at $490 \mathrm{~nm}$ using a microplate reader (Bio-Rad Laboratories, Inc. Hercules, CA, USA).

Western blot analysis. SW1990 cells were treated with PBS (as control), metformin $20 \mathrm{mmol} / \mathrm{l}$, rapamycin $200 \mathrm{ng} / \mathrm{ml}$ or metformin $20 \mathrm{mmol} / 1$ + rapamycin $200 \mathrm{ng} / \mathrm{ml}$ at $37^{\circ} \mathrm{C}$ for $24 \mathrm{~h}$. The cells were then lysed in a Radioimmunoprecipitation Assay (RIPA) Lysis and Extraction Buffer (Thermo Fisher Scientific, Inc.). Protein $(\sim 15 \mu \mathrm{g})$ from each sample was extracted in RIPA Lysis and Extraction Buffer and quantified using a Bicinchoninic Acid Protein Assay kit (Thermo Fisher Scientific, Inc.). Then protein was separated using SDS-PAGE (5-10\% gel) and electro-transferred to polyvinylidene fluoride membranes (Millipore, Bedford, MA, USA). The membrane was blocked with 5\% nonfat dry milk in Tris-buffered saline Tween-20 at room temperature for $1 \mathrm{~h}$. The membranes were incubated overnight at $4{ }^{\circ} \mathrm{C}$ with primary antibodies directed against EGFR (1:1,000), VEGF (1:1,000), Bcl-2 (1:1,000), AMPK (1:500), p-AMPK (1:500), mTOR (1:500) and p-mTOR (1:500), then with secondary antibodies for $1 \mathrm{~h}$ at room temperature. Anti-rabbit IgG, HRP-linked antibody $(1: 2,000)$ was used to test AMPK, p-AMPK, mTOR, p-mTOR, and EGFR, and anti-mouse IgG, HRP-linked antibody $(1: 2,000)$ was used to test Bcl-2 and VEGF. Then, immunoblot analysis was performed. $\beta$-actin $(1: 1,000)$ served as the loading control, and the corresponding secondary antibody was anti-rabbit IgG, HRP-linked antibody (1:2,000).

The level of protein expression was examined using a Novex ${ }^{\circledR}$ enhanced chemiluminescence Chemiluminescent Substrate Reagent kit (Thermo Fisher Scientific, Inc.) and performed according to the manufacturer's protocol and quantified using Image J software (V1.48; National Institutes of Health, Bethesda, MD, USA). Protein expression was presented as the percentage of the corresponding control.

Xenograft model. A total of 24 male $n u / n u$ mice aged 4-5 week old with body weight ranged 15-20 g were supplied by SLAC Laboratory Animal Co., Ltd. (Shanghai, China). The mice were maintained in a specific pathogen-free facility, at a temperature of $23 \pm 2^{\circ} \mathrm{C}, 50-60 \%$ humidity, a light/dark cycle of $12 / 12 \mathrm{~h}$ and given free access to water and a standard rodent chow diet.

The new bought mice were housed for 3 days prior to any medical intervention. SW1990 cells $\left(2 \times 10^{6}\right)$ were injected subcutaneously into the right flank of the mice (day 0). When the mean diameter of the tumors reached $2 \mathrm{~mm}$ (at $\sim 1$ week), the animals were randomly divided into four groups: i) The untreated group (control); ii) the metformin group; iii) the rapamycin group; and iv) the combination group ( $n=6 /$ group). Metformin (200 mg/kg body weight) was administered once daily by oral gavage and rapamycin $(2.0 \mathrm{mg} / \mathrm{kg}$ body weight) was delivered by intraperitoneal injection every other day to the appropriate groups for a total of 3 weeks. The tumor dimensions were measured by calipers a minimum of twice a week. Tumor volume was calculated according to the following formula: Tumor volume $=$ length $\mathrm{x}$ width ${ }^{2} \mathrm{x} 0.5$. Once the tumor volume reached $3 \mathrm{~cm}^{3}$ or significant body weight loss was observed, the treatment was stopped and the mice were sacrificed.

The present study was approved by the Animal Ethical and Welfare Committee of Nanjing Medical University (Nanjing, China). The experimental procedures all complied with the guide for the care and use of laboratory animals (13).

Immunohistochemical (IHC) analysis. The mice were anesthetized and euthanized by cervical dislocation at day 28 and the xenograft tumors were surgically removed. Tumors from xenograft cells were fixed in $10 \%$ neutralized buffered formalin for $48 \mathrm{~h}$ at room temperature and embedded in paraffin. Tissue sections were cut 5- $\mu \mathrm{m}$-thick for hematoxylin and eosin (H\&E) staining and IHC analysis. The sections were stained with $0.5 \%$ $\mathrm{H} \& \mathrm{E}$ for $4 \mathrm{~min}$ in each dye, at room temperature. Light microscopic examination was performed for histological diagnosis. IHC staining was performed in accordance with standard protocols (14). Briefly, non-specific binding was inhibited with Biocare blocking reagent (Biocare Medical, Concord, CA, USA) for $30 \mathrm{~min}$ at room temperature followed by incubation with anti-human polyclonal IgG primary antibodies directed against AMPK (1:200), p-AMPK (1:200), mTOR (1:100), p-mTOR (1:100), VEGF (1:200), EGFR (1:200) and Bcl-2 (1:200) at $4^{\circ} \mathrm{C}$ overnight, then with secondary antibodies at room temperature for $30 \mathrm{~min}$. Anti-rabbit IgG, HRP-linked antibody (1:200) was used to test AMPK, p-AMPK, mTOR, p-mTOR, and EGFR, and anti-mouse IgG, HRP-linked antibody (1:200) was used to test Bcl-2 and VEGF. Images of all sections were captured using a Nikon MODEL ECLIPSE Ci-L microscope (Nikon Corporation, Tokyo, Japan). IHC pictures were captured at magnification, x100 times and H\&E pictures were captured at magnification, x200 times.

Statistical analysis. All data are presented as the mean \pm standard deviation (SD) of a minimum of three independent experiments. The data was analyzed using SPSS software version 22.0 (IBM Corp., Armonk, NY, USA). Multiple groups were analyzed using one-way analysis of variance with the Dunnet post hoc test. $\mathrm{P}<0.05$ was considered to indicate a statistically significant difference. The combination index (CI) devised by Chou and Talalay (1984) (15) was calculated using CompuSyn software version 1.0 (ComboSyn, Inc., Paramus, NJ, USA) (which was updated online periodically) to ascertain whether the combination of metformin and rapamycin was additive $(\mathrm{CI}=1)$, antagonistic $(\mathrm{CI}>1)$ or synergistic $(\mathrm{CI}<1)$. Synergism $(\mathrm{CI}<1)$ suggests greater than expected additive effect, additive effect $(\mathrm{CI}=1)$ suggests the combined effect predicted by the mass-action law principle in the absence of synergism or antagonism, and antagonism $(\mathrm{CI}>1)$ suggests smaller than expected additive effect (16). 


\section{Results}

Metformin and rapamycin synergistically inhibit the proliferation of PC cells in vitro. An MTT assay was conducted to analyze the viability of SW1990 cells following treatment with metformin, rapamycin or a combination of the two substances at varying concentrations (Fig. 1). Metformin (5-20 $\mathrm{mmol} / \mathrm{l})$ significantly inhibited the proliferation of SW1990 cells in comparison with the control group. Low concentrations of rapamycin $(0.2,2$ and $20 \mathrm{ng} / \mathrm{ml})$ did not significantly change cell viability compared with the control group. The viability of SW1990 cells was significantly suppressed by rapamycin at the concentration of $200 \mathrm{ng} / \mathrm{ml}$.

To analyze the interaction between metformin and rapamycin, the Chou and Talalay method (1984), was used (15). The CI values were as follows: Combination A, 21483.8; combination $\mathrm{B}, 0.42$; combination $\mathrm{C}, 0.39$; combination $\mathrm{D}$, 0.18 . These results suggest that the combination of metformin and rapamycin synergistically inhibited the growth of SW1990 cells when administered at higher concentrations (B-D).

In subsequent experiments the concentrations of $20 \mathrm{mmol} / \mathrm{l}$ metformin and $200 \mathrm{ng} / \mathrm{ml}$ rapamycin were selected for use.

Western blot analysis. To explore the underlying mechanisms responsible for the synergy of combination treatment, the effects of metformin and rapamycin on the expression of selected proteins were investigated by western blot analysis (Fig. 2A).

No significant differences were observed in the protein expression of EGFR in any treatment group (Fig. 2B). The results suggested that metformin treatment alone significantly increased p-AMPK protein expression (Fig. 2C), but significantly decreased the protein expression of VEGF (Fig. 2D), p-mTOR (Fig. 2E) and Bcl-2 compared with the control (Fig. 2F). Rapamycin treatment alone significantly suppressed p-mTOR protein expression compared with the control. The combination treatment significantly increased p-AMPK protein expression, whereas it significantly decreased VEGF, Bcl-2 and p-mTOR protein expression compared with the control. Combination treatment also significantly reduced p-mTOR protein expression compared with metformin or rapamycin treatment alone, which indicates the synergistic action of metformin and rapamycin.

Xenograft model. To assess the antitumor efficacy of metformin and rapamycin upon $\mathrm{PC}$ in vivo, a xenograft model was developed using $n u / n u$ mice. It was observed that at the final time point (day 28), the tumor volumes differed significantly among the four groups (Fig. 3). The administration of metformin alone had a small inhibitory effect and the injection of rapamycin alone had a moderate inhibitory effect. However, the combination of metformin and rapamycin exerted a significantly increased inhibition of tumor growth compared with the control group, the rapamycin monotherapy group and the metformin monotherapy group.

No significant loss of body weight was observed in the mice in the three treatment groups during the 3-week therapy period, which suggests that the therapy was well tolerated with no obvious toxicity (data not shown). The protein

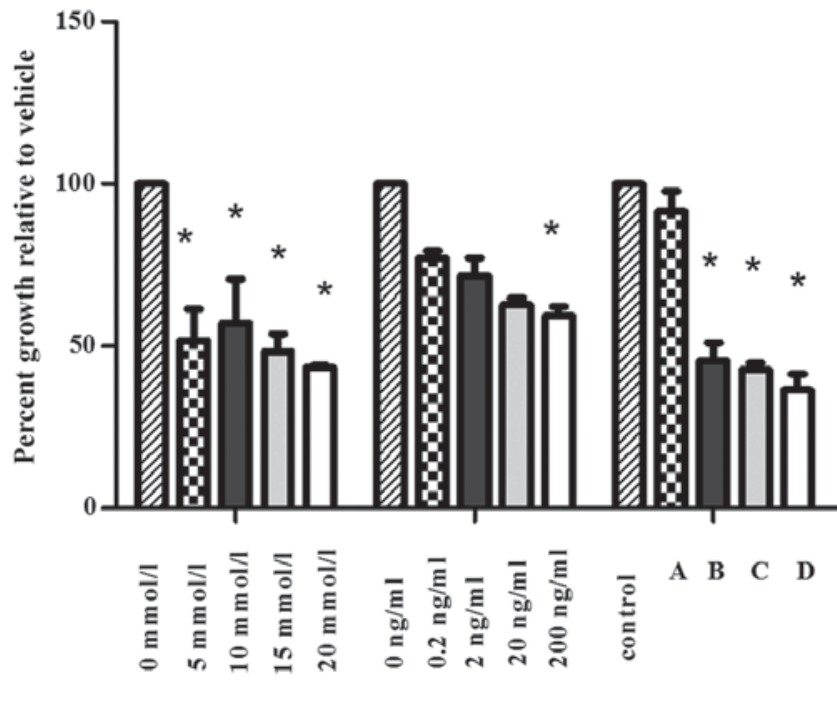

Figure 1. Treatment with metformin and rapamycin inhibits the growth of SW1990 pancreatic cancer cells in vitro. SW1990 pancreatic cells were treated with varying concentrations of metformin and rapamycin, either in isolation or combination. The proliferation results from three independent experiments are expressed as a percentage of the corresponding untreated controls. ${ }^{*} \mathrm{P}<0.05$ vs. untreated control. A, metformin $5 \mathrm{mmol} / 1+$ rapamycin $0.2 \mathrm{ng} / \mathrm{ml}$; B, metformin $10 \mathrm{mmol} / 1+$ rapamycin $2 \mathrm{ng} / \mathrm{ml}$; C, metformin $15 \mathrm{mmol} / \mathrm{l}$ + rapamycin $20 \mathrm{ng} / \mathrm{ml} ; \mathrm{D}$, metformin $20 \mathrm{mmol} / 1$ + rapamycin $200 \mathrm{ng} / \mathrm{ml}$.

expression of p-mTOR in the mouse tumors was detected by IHC analysis (Fig. 4A-D). Fig. 4A demonstrated that p-mTOR was expressed in the tumors in the control group. It was observed that metformin (Fig. 4C) and rapamycin (Fig. 4D) alone decreased p-mTOR expression, and, when they were administered in combination (Fig. 4B), they notably decreased p-mTOR expression to a higher degree. H\&E staining (Fig. 4E) of the sections from control group was performed to ensure the diagnosis of pancreatic cancer of tumors from xenograft. These results further demonstrate that the administration of a combination of metformin and rapamycin confers enhanced anti-PC activity.

\section{Discussion}

Multiple types of cancer, including PC, are characterized by aberrant activation of mTOR (17). Targeting of the mTOR signaling pathway may be an effective therapeutic strategy to minimize the progression of PC. Metformin and rapamycin inhibit the growth of PC cells by suppressing the mTOR signaling pathway (12). It has been previously reported that a low dose of rapamycin $\left(10^{-10} \mathrm{~mol} / \mathrm{l}\right)$ does not suppress the growth of PC cells, whereas a high dose $\left(10^{-8} \mathrm{~mol} / \mathrm{l}\right)$ does (18). In the present study, rapamycin at lower concentrations $(0.2,2$ and $20 \mathrm{ng} / \mathrm{ml})$ did not significantly inhibit the proliferation of PC cells, whereas $200 \mathrm{ng} / \mathrm{ml}$ rapamycin did. The metformin dose of $200 \mathrm{mg} / \mathrm{kg}$ body weight was used in the xenograft experiments. However, millimolar concentrations of metformin were used in vitro, despite the maximum concentration used in vivo being at the micromolar level, which explained why the anti-cancer effect of metformin was not as notable in vivo as in vitro. 
A

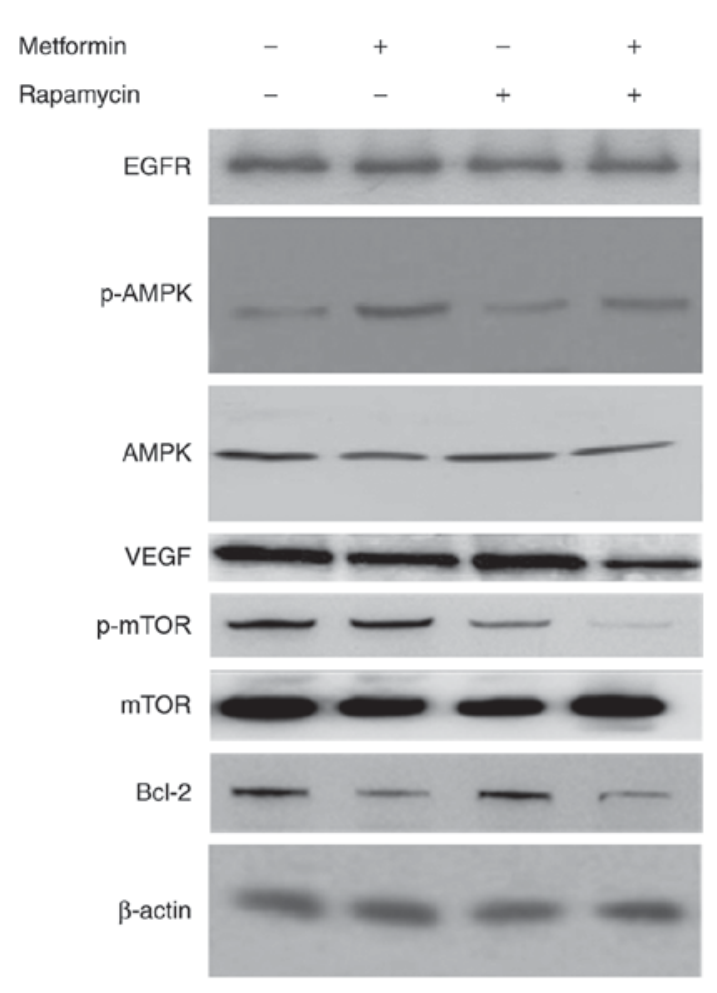

E

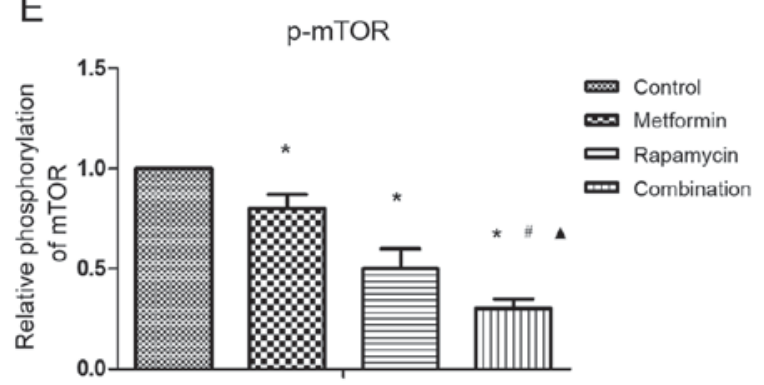

B

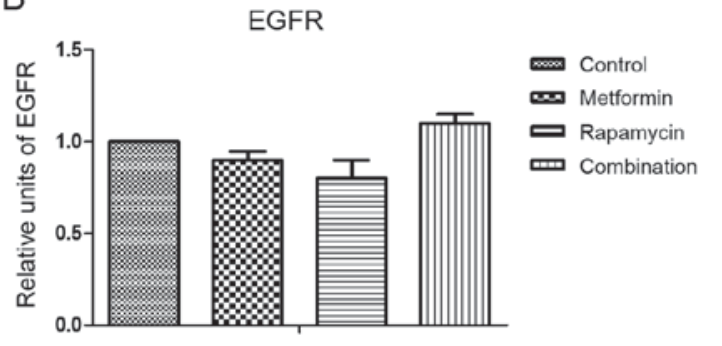

C

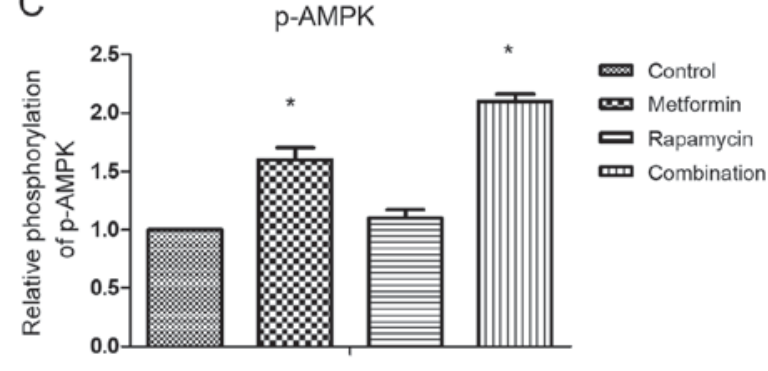

D

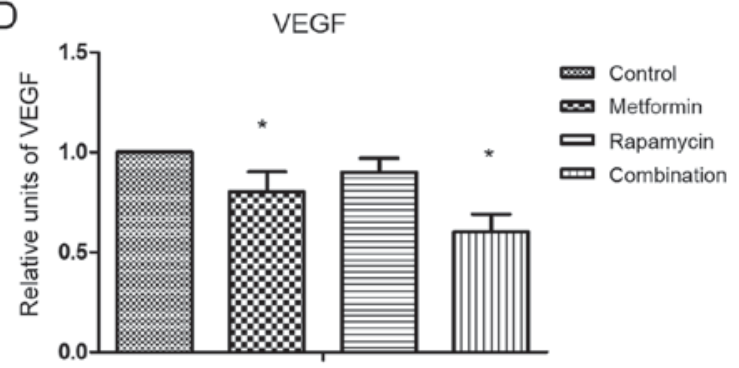

$\mathrm{F}$

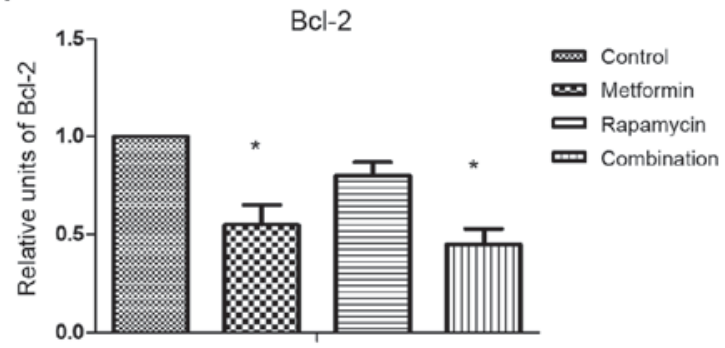

Figure 2. Treatment with metformin and rapamycin affects protein expression in SW1990 cells. (A) Protein expression levels of the indicated proteins were measured by western blot analysis. The results of this analysis were quantified by densitometric analyses and the relative protein expression levels of (B) EGFR, (C) p-AMPK, (D) VEGF, (E) p-mTOR and (F) Bcl-2 are indicated. ${ }^{*} \mathrm{P}<0.05$ vs. control; ${ }^{\#} \mathrm{P}<0.05$ vs. the metformin group; ${ }^{\wedge} \mathrm{P}<0.05$ vs. the rapamycin group. EGFR, epidermal growth factor receptor; p-, phosphorylated; AMPK, adenosine monophosphate-activated protein kinase; VEGF, vascular endothelial growth factor; Bcl-2, B-cell lymphoma 2.

Although rapamycin and metformin suppress the mTOR signaling pathway (rapamycin directly and metformin by AMPK signaling), rapamycin is known to activate protein kinase B (AKT), which may reduce its anti-tumor activity, whereas metformin treatment decreases AKT activation (19). Metformin and rapamycin affect other distinct targets, including microRNAs (miRs), which regulate gene expression following transcription (20). Rapamycin targets are focused on survival signaling and decreased mTOR-associated growth, through increasing the expression of cell cycle-regulating miRs and the let-7b miR precursor (12). Metformin directly targets Notch, Snail and Slug and reduces the levels of glucose, insulin and miR-34a expression (12). Metformin and rapamycin inhibit the growth of PC cells through shared and distinct mechanisms, which indicates that the integration of metformin into the treatment regimen of rapamycin may enhance its anti-tumor activity.

In the present study, metformin and rapamycin exhibited synergic effects at concentrations of metformin $(10-20 \mathrm{mmol} / \mathrm{l})+$ rapamycin $(2-200 \mathrm{ng} / \mathrm{ml})$. The underlying mechanisms of their action were further investigated by western blot analysis and it was revealed that metformin $(20 \mathrm{mmol} / \mathrm{l})$ combined with rapamycin $(200 \mathrm{ng} / \mathrm{ml})$ suppressed the phosphorylation of mTOR significantly compared with monotherapy. Treatment with metformin and rapamycin alone 


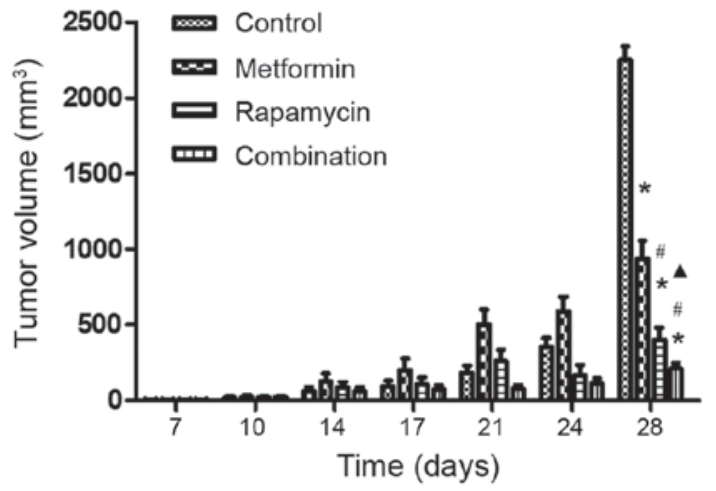

Figure 3. Effects of treatment with metformin and rapamycinon on tumor size in a mouse model. Mice were treated with rapamycin and metformin either in isolation or combination and the size of their tumors were measured over a period of 28 days ( $n=6 /$ group). At the end of the study ( 28 days), statistical difference of the tumor size was observed. ${ }^{*} \mathrm{P}<0.05$ vs. the control group; ${ }^{\#} \mathrm{P}<0.05$ vs. the metformin group; ${ }^{\wedge} \mathrm{P}<0.05$ vs. the rapamycin group.
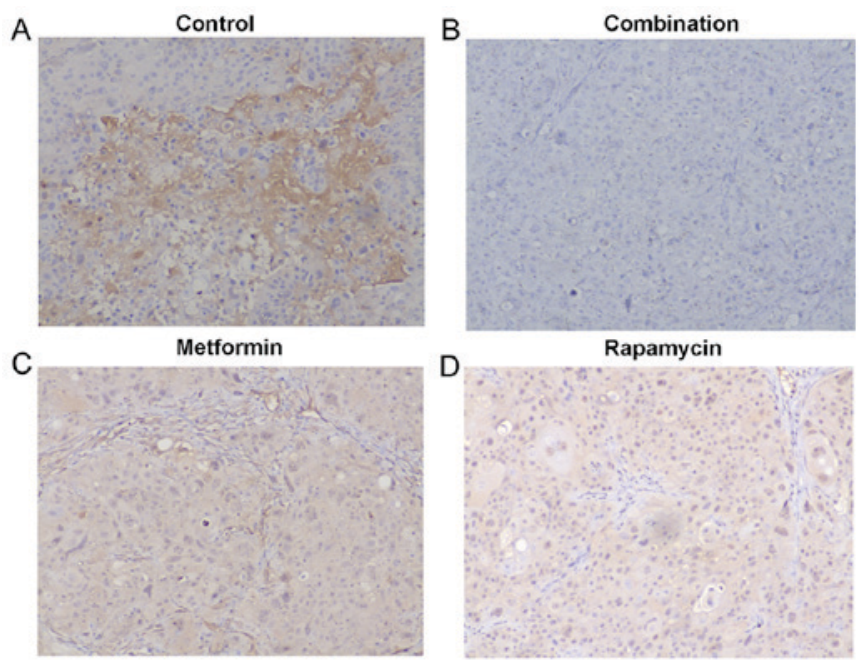

E

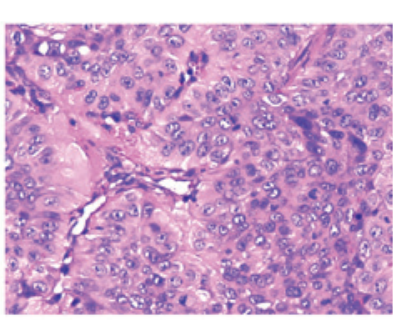

Figure 4. IHC analyses of pancreatic cancer tumors removed from mice. Representative images of xenograft tumors expressing phosphorylatedmammalian target of rapamycin by IHC staining in the (A) control group, (B) combination treatment group, (C) metformin treatment group and (D) rapamycin treatment group (all magnification, x100). (E) A representative image of hematoxylin andeosin staining of xenograft tumors removed from mice in the control group (magnification, x200). IHC, immunohistochemical.

inhibited the growth of PC in vivo, and treatment with them in combination consistently exhibited an enhanced effect. IHC analyses of xenograft tumors demonstrated a stronger suppression of p-mTOR in the combination treatment group compared with the monotherapy groups.

The combination of metformin and rapamycin has been reported to inhibit cancer progression by their combined effects on the mTORC1 signaling pathway and tissue inflammation (21). When metformin is combined with everolimus, it may exert a synergistic inhibition of cancer growth by abrogation of the phosphorylation of S6 and 4E-binding protein 1 (22). Metformin in combination with dexamethasone has been demonstrated to repress the expression of myeloid cell leukemia-1 and activate caspase 3, as well as increasing the number of cells in the G1 phase of the cell cycle (23). A previous study reported that metformin combined with vemurafenib may induce apoptosis and result in the synergistic inhibition of the growth of cancer cells, suggesting that metformin reverses the resistance of cancer cells to vemurafenib by altering the cellular energy balance (24). Metformin and salicylate may synergistically reduce the survival of cancer cells in vitro by inhibiting de novo lipogenesis and targeting pro-apoptotic and Bcl-2 family members $(25,26)$. Metformin also synergizes with chemotherapy to reverse multi-drug resistance in cancers by targeting the AMPK/mTOR/hypoxia inducible factor-1 $\alpha / \mathrm{P}$-glycoprotein/multidrug resistance-associated protein 1 signaling pathway $(27,28)$. Metformin potentiates the anti-tumor effect of resveratrol on PC by targeting the VEGF-B signaling pathway (29).

It has been hypothesized that the combination of targeted mTOR inhibition by rapamycin with the broader inhibition provided by metformin may lead to a greater-than-additive inhibition of growth of PC cells. In the present study, treatment with metformin alone or in combination with rapamycin significantly suppressed the expression of VEGF and Bcl-2 compared with the control, however, no significant differences were detected between the combination treatment and metformin treatment alone.

Previous studies have revealed that rapamycin therapy for PC patients was not effective and the efficacy of metformin in vivo was contradictory in many studies (30-36). The present study demonstrated the anti-tumor action of metformin and revealed the synergistic action of metformin and rapamycin in the treatment of PC cells by the downregulation of the mTOR signaling pathway. Other pathways may also be affected by this synergistic treatment, including apoptosis activation or VEGF inhibition, however this requires further study to confirm. A combination of metformin and rapamycin may represent a promising anti-tumor therapy for patients with PC. Additional studies are required to investigate the mechanisms by which the synergy functions and to verify its efficacy in the treatment of patients with PC.

\section{Acknowledgements}

The present study was supported by Nanjing Medical University (grant no. 2015NJMU138).

\section{References}

1. Siegel RL, Miller KD and Jemal A: Cancer statistics, 2016. CA Cancer J Clin 66: 7-30, 2016.

2. Chen W, Zheng R, Baade PD, Zhang S, Zeng H, Bray F, Jemal A Yu XQ and He J: Cancer statistics in China, 2015. CA Cancer J Clin 66: 115-132, 2016.

3. Ding B, Wahid MA, Wang Z, Xie C, Thakkar A, Prabhu S and Wang J: Triptolide and celastrol loaded silk fibroin nanoparticles show synergistic effect against human pancreatic cancer cells. Nanoscale 9: 11739-11753, 2017. 
4. Soranna D, Scotti L, Zambon A, Bosetti C, Grassi G, Catapano A, La Vecchia C, Mancia G and Corrao G: Cancer risk associated with use of metformin and sulfonylurea in type 2 diabetes: A meta-analysis. Oncologist 17: 813-822, 2012.

5. Sadeghi N, Abbruzzese JL, Yeung SC, Hassan M and Li D: Metformin use is associated with better survival of diabetic patients with pancreatic cancer. Clin Cancer Res 18: 2905-2912, 2012.

6. Bodmer M, Becker C, Meier C, Jick SS and Meier CR: Use of antidiabetic agents and the risk of pancreatic cancer: A case-control analysis. Am J Gastroenterol 107: 620-626, 2012.

7. Lee MS, Hsu CC, Wahlqvist ML, Tsai HN, Chang YH and Huang YC: Type 2 diabetes increases and metformin reduces total, colorectal, liver and pancreatic cancer incidences in Taiwanese: A representative population prospective cohort study of 800,000 individuals. BMC Cancer 11: 20, 2011.

8. Mohammed A, Janakiram NB, Brewer M, Ritchie RL, Marya A, Lightfoot S, Steele VE and Rao CV: Antidiabetic drug metformin prevents progression of pancreatic cancer by targeting in part cancer stem cells and mTOR signaling. Transl Oncol 6: 649-659, 2013.

9. Karnevi E, Said K, Andersso R and Rosendahl AH: Metformin-mediated growth inhibition involves suppression of the IGF-I receptor signalling pathway in human pancreatic cancer cells. BMC Cancer 13: 235, 2013.

10. Soares HP, Ni Y, Kisfalvi K, Sinnett-Smith J and Rozengurt E: Different patterns of Akt and ERK feedback activation in response to rapamycin, active-site mTOR inhibitors and metformin in pancreatic cancer cells. PLoS One 8: e57289, 2013.

11. Vallianou NG, Evangelopoulos A and Kazazis C3: Metformin and cancer. Rev Diabet Stud 10: 228-235, 2013.

12. Cifarelli V, Lashinger LM, Devlin KL, Dunlap SM, Huang J, Kaaks R, Pollak MN and Hursting SD: Metformin and rapamycin reduce pancreatic cancer growth in obese prediabetic mice by distinct microRNA-regulated mechanisms. Diabetes 64: 1632-1642, 2015

13. National Research Council: Guide for the Care and Use of Laboratory Animals. 8th edition. National Acadamies Press. Washington, DC, 2011

14. Simon R, Mirlacher M and Sauter G: Immunohistochemical analysis of tissue microarrays. Methods Mol Biol 664: 113-126, 2010.

15. Chou TC and Talalay P: Quantitative analysis of dose-effect relationships: The combined effects of multiple drugs or enzyme inhibitors. Adv Enzyme Regul 22: 27-55, 1984.

16. Chou TC and Martin N: CompuSyn for drug combinations and for general dose-effect analysis. Combosyn, Inc., Paramus, NJ, 2005.

17. Guertin DA and Sabatini DM: An expanding role for mTOR in cancer. Trends Mol Med 11: 353-361, 2005.

18. Rice S, Pellat L, Ahmetaga A, Bano G, Mason HD and Whitehead SA: Dual effect of metformin on growth inhibition and oestradiol productionin breast cancer cells. Int J Mol Med 35: 1088-1094, 2015

19. Zakikhani M, Blouin MJ, Piura E and Pollak MN: Metformin and rapamycin have distinct effects on the AKT pathway and proliferation in breast cancer cells. Breast Cancer Res Treat 123 271-279, 2010

20. Bartel DP: MicroRNAs: Genomics, biogenesis, mechanism, and function. Cell 116: 281-297, 2004.

21. Saha A, Blando J, Tremmel L and DiGiovanni J: Effect of metformin, rapamycin, and their combination on growth and progression of prostate tumors in HiMyc mice. Cancer Prev Res (Phila) 8: 597-606, 2015.
22. Wang Y, Wei J, Li L, Fan C and Sun Y: Combined use of metformin and everolimus is synergistic in the treatment of breast cancer cells. Oncol Res 22: 193-201, 2014.

23. Zi FM, He JS, Li Y, Wu C, Yang L, Yang Y, Wang LJ, He DH, Zhao Y, Wu WJ, et al: Metformin displays anti-myeloma activity and synergistic effect with dexamethasone in in vitro and in vivo xenograft models. Cancer Lett 356: 443-453, 2015.

24. Hanly EK, Bednarczyk RB, Tuli NY, Moscatello AL, Halicka HD, Li J, Geliebter J, Darzynkiewicz Z and Tiwari RK: mTOR inhibitors sensitize thyroid cancer cells to cytotoxic effect of vemurafenib. Oncotarget 6: 39702-39713, 2015

25. O'Brien AJ, Villani LA, Broadfield LA, Houde VP, Galic S, Blandino G, Kemp BE, Tsakiridis T, Muti P and Steinberg GR: Salicylate activates AMPK and synergizes with metformin to reduce the survival of prostate and lung cancer cells ex vivo through inhibition of de novo lipogenesis. Biochem J 469: 177-187, 2015.

26. Yue W, Zheng X, Lin Y, Yang CS, Xu Q, Carpizo D, Huang H, DiPaola RS and Tan XL: Metformin combined with aspirin significantly inhibit pancreatic cancer cell growth in vitro and in vivo by suppressing anti-apoptotic proteins Mcl-1 and Bcl-2. Oncotarget 6: 21208-21224, 2015.

27. Ling S, Feng T, Ke Q, Fan N, Li L, Li Z, Dong C, Wang C, Xu F, $\mathrm{Li}$ Y and Wang L: Metformin inhibits proliferation and enhances chemosensitivity of intrahepatic cholangiocarcinoma cell lines. Oncol Rep 31: 2611-2618, 2014.

28. Ling S, Tian Y, Zhang H, Jia K, Feng T, Sun D, Gao Z, Xu F, Hou Z, Li Y and Wang L: Metformin reverses multidrug resistance in human hepatocellular carcinoma Bel-7402/5-fluorouracil cells. Mol Med Rep 10: 2891-2897, 2014.

29. Zhu M, Zhang Q, Wang X, Kang L, Yang Y, Liu Y, Yang L, Li J, Yang L, Liu J, et al: Metformin potentiates anti-tumor effect of resveratrol on pancreatic cancer by down-regulation of VEGF-B signaling pathway. Oncotarget 7: 84190-84200, 2016.

30. Driscoll DR, Karim SA, Sano M, Gay DM, Jacob W, Yu J, Mizukami Y, Gopinathan A, Jodrell DI, Evans TR, et al: mTORC2 Signaling drives the development and progression of pancreatic cancer. Cancer Res 76: 6911-6923, 2016.

31. Lipner MB, Marayati R, Deng Y, Wang X, Raftery L, O'Neil BH and Yeh JJ: Metformin treatment does not inhibit growth of pancreatic cancer patient-derived Xenografts. PLoS One 11: e0147113, 2016.

32. Wei F, Zhang Y, Geng L, Zhang P, Wang G and Liu Y: mTOR inhibition induces EGFR feedback activation in association with its resistance to human pancreatic cancer. Int J Mol Sci 16: 3267-3282, 2015.

33. Zagouri F, Sergentanis TN, Chrysikos D, Zografos CG, Papadimitriou CA, Dimopoulos MA, Filipits M and Bartsch R: Molecularly targeted therapies in metastatic pancreatic cancer: A systematic review. Pancreas 42: 760-773, 2013

34. Garrido-Laguna I, Tan AC, Uson M, Angenendt M, Ma WW, Villaroel MC,Zhao M, Rajeshkumar NV,Jimeno A,Donehower R, et al: Integrated preclinical and clinical development of mTOR inhibitors in pancreatic cancer. Br J Cancer 103: 649-655, 2010.

35. Javle MM, Shroff RT, Xiong H, Varadhachary GA, Fogelman D, Reddy SA, Davis D, Zhang Y, Wolff RA and Abbruzzese JL: Inhibition of the mammalian target of rapamycin (mTOR) in advanced pancreatic cancer: Results of two phase II studies. BMC Cancer 10: 368, 2010.

36. Wolpin BM, Hezel AF, Abrams T, Blaszkowsky LS, Meyerhardt JA, Chan JA, Enzinger PC, Allen B, Clark JW, Ryan DP and Fuchs CS: Oral mTOR inhibitor everolimus in patients with gemcitabine-refractory metastatic pancreatic cancer. J Clin Oncol 27: 193-198, 2009. 